Check for updates

Cite this: RSC Adv., 2019, 9, 31735

Received 18th June 2019 Accepted 7th September 2019

DOI: 10.1039/c9ra04563e

rsc.li/rsc-advances

\section{In situ generated hydrophobic micro ripples via $\pi-$ $\pi$ stacked pop-up reduced graphene oxide nanoflakes for extended critical heat flux and thermal conductivities $\uparrow$}

\begin{abstract}
Ravi Kumar Cheedarala (D) * and Jung II Song*
We report the synthesis of thermally heated pop-up reduced graphene oxide (Pop-rGO) and its nanofluid (Pop-rGO-Nf) in DI water for extended critical heat flux (CHF) in a nucleate pool boiling experiment. When Pop-rGO-Nf is boiled over a nichrome (NiCr) wire heater the CHF values were increased up to $132 \%, 156 \%$, and $175 \%$ with increasing concentrations of 0.0005 vol\%, 0.001 vol\%, and 0.005 vol\% at heat fluxes of $q^{\prime \prime}=$ $264333 \mathrm{~kW} \mathrm{~m}^{-2}, 339202 \mathrm{~kW} \mathrm{~m}^{-2}$, and $327895 \mathrm{~kW} \mathrm{~m}^{-2}$, respectively, because of the higher surface area of $430 \mathrm{~m}^{2} \mathrm{~g}^{-1}$. We also found a decrease in the CHF value from 0.05 vol\% (175\%) to 0.01 vol\% (153\%) for Pop$\mathrm{rGO}-\mathrm{Nf}$ due to the nanofluid concentration reaching the saturation point. After nucleate pool boiling, the developed Pop-rGO-Nf built-up layer on the $\mathrm{NiCr}$ wire surface showed regular $\pi-\pi$ stacking with novel micro-rippled structures having uniform nanocavities and nanochannels. The nanocavities strongly helped vapor bubbles to escape from the $\mathrm{NiCr}$ wire surface. In addition, the nanochannels were formed by hydrogen bonding of adjacent carboxyl groups of each Pop-rGO nanosheet. The surface hydrophobicity of the built-up layers increased with the increase of the concentration of the Pop-rGO$\mathrm{Nfs}$, and the surface morphology, roughness average $\left(R_{\mathrm{a}}\right)$ and hydrophobicity were determined using FESEM, AFM and contact angle (CA) analysis. In our present investigation, during and after the nucleate CHF experiments with Pop-rGO-Nfs, for the first time, we obtained a higher CHF value of $175 \%$ at 0.01 vol\% and a higher CA of $118^{\circ}$ obtained at 0.05 vol\%, due to the increase in surface hydrophobicity and the novel micro-rippled structures. We anticipate that the present results suggest that pool boiling employing Pop-rGO-Nf can dissipate the critical heat flux of electronic chips to a greater extent, allowing the enhancement of the cooling performance in existing two-phase heat transfer devices.
\end{abstract}

\section{Introduction}

Nanofluids (Nfs) have great importance within current research in scientific and industrial fields due to their unprecedented properties such as high surface area for heat transfer between the particles and the base fluids, high dispersion stability with superior Brownian motion of particles, reduced particle clogging, and tunable high thermal conductivity and wettability. ${ }^{1}$ Nfs are a colloidal mixture of nanoparticles in base fluids, and they are one of the best alternatives to enhance critical heat flux (CHF). ${ }^{2}$ The CHF is a process of vigorous heat transfer that occurs with a phase change from liquid to vapor in a pool of initially quiescent liquid. To date, various $\mathrm{Nfs}$, including $\mathrm{Al}_{2} \mathrm{O}_{3},{ }^{3}$ $\mathrm{TiO}_{2},{ }^{4} \mathrm{ZnO}_{2},{ }^{5} \mathrm{CuO},{ }^{6} \mathrm{Fe}_{3} \mathrm{O}_{4},{ }^{7} \mathrm{Au},{ }^{4} \mathrm{Ag},{ }^{8} \mathrm{CNTs}^{9}$ and graphenes ${ }^{6,10}$ have been investigated in order to enhance the CHF through

Department of Mechanical Engineering, Changwon National University, Changwon, 51140, Republic of Korea.E-mail: rkchidrala@gmail.com; jisong@changwon.ac.kr

$\dagger$ Electronic supplementary information (ESI) available. See DOI: 10.1039/c9ra04563e nucleate boiling heat transfer (BHT). The BHT method is used in nuclear power plants, in electric chip cooling, in air conditioners, and in refrigerators. BHT is characterized by the heat flux $\left(\mathrm{W} \mathrm{m}^{-2}\right)$ and wall temperature $\left({ }^{\circ} \mathrm{C}\right)$ of the surface of the heater during vapor bubble generation from the surface of the wire. ${ }^{11}$ The CHF phenomenon is complex, difficult to understand, irreversible, and unpredictable; thus, many studies have tried to analyze CHF conditions for thermal systems in order to avoid encountering dangerous situations such as increases in the wall temperature by vapor cover and the breaking of wires etc. ${ }^{\mathbf{1 2}}$ Researchers have tried many times to increase CHF for effective and safer heat transfer using improved heater-surface wettability and morphology such as in micro/nano-structured heater surfaces. ${ }^{13}$ The enhancement of CHF is related to the build-up of a deposition layer of nanoparticles during the boiling of Nfs. In order to determine $\mathrm{CHF}$, some scientists have alternatively showed that the morphology of the deposition layer improved both surface wettability and capillarity. ${ }^{14}$ Thus, changing the microstructure and physicochemical properties of the surface during boiling is one of the important factors in 
CHF enhancement. Many reports have shown that surfaces with deposited nanoparticles have significantly greater wettability than bare surfaces. ${ }^{15}$ In addition, previously our group has reported the experimental study of hydrophilic $\mathrm{CuO}-$ chitosan (CS) nanofluid templates for extended CHFs and achieved up to 79\% using 0.06 wt\% CuO-CS NF. ${ }^{16}$ In light of these results, we therefore started with the idea for the present work, which is to enhance CHF by choosing a pop-up reduced graphene oxide nanofluid (Pop-rGO-Nf) for better thermal conductivity and selfstacking characteristics to form a more advantageous rippled structure to increase $\mathrm{CHF}$.

Graphene oxide (GO) has attracted great interest because of its unique physical properties that arise from its single layer thick planar sheet assembled with $\mathrm{sp}^{2}$ bonded carbon atoms in a hexagonal two dimensional (2D) lattice structure. ${ }^{16-25}$ Few layered GO structures have been attractive for heat transfer applications because of their higher thermal conductivity maximum up to 3000$5300 \mathrm{~W} \mathrm{~m}{ }^{-1} \mathrm{~K}^{-1} \cdot{ }^{26}$ Reduced graphene oxide (rGO) is commonly prepared from GO by chemical and thermal routes. ${ }^{27,28}$ We adapted this method with minor modifications to generate reduced graphene oxide as Pop-rGO from GO at ambient conditions. The resulting Pop-rGO showed a high surface area of $430 \mathrm{~m}^{2} \mathrm{~g}^{-1}$ in the Brunauer Emmett Teller (BET) test. ${ }^{29-31}$ Recently, Ahn et al. investigated a three-dimensional rGO foam to prevent heater surface failure during boiling heat transfer using a colloid on a rectangular sheet. ${ }^{14,15}$ In another study, Baby et al. reported the synthesis and transport properties of dispersed metal oxide-decorated graphene $\mathrm{Nfs}$ for thermal conductivity enhancement up to $28 \%$ using 0.05 vol\% of CuO decorated graphene in DI water. ${ }^{33}$ These studies only focused on thermal conductivity rather than CHF enhancement. However, all of these methods used a higher vol\% of Nfs to obtain the enhanced CHF values. Despite the urgent need for the development of alternative graphene-based Nfs that are environmentally benign, mild and cost-effective methods remain a challenge.

In order to overcome the above challenges in enhancing $\mathrm{CHF}$, we introduce for the first time a Pop-rGO-Nf in DI water. Here, self-stacked 3D-networked Pop-rGO nanosheets containing regular nanochannels and a well-organized micro/nano morphological structured network by a self-stacking phenomenon at the basal planes and hydrogen bonding at the adjacent carboxylic acids are used..$^{31}$ We use four different Pop-rGO-Nfs, which are $0.0005,0.001,0.05$ and 0.01 vol\%, for the $\mathrm{CHF}$ nucleate pool boiling experiments. An enhanced CHF value of up to $175 \%$ was observed for 0.005 vol\% of Pop-rGO-Nf, which is significantly greater than that of other commercial and graphene-based Nfs. To our knowledge, no research has been published to date on nucleate pool boiling CHF experiments using Pop-rGO-Nf, with the exception of a few reports concerning $x$ Graphene Nano Particles ( $x$ GNPs) and rGO/GO mixtures as Nfs, Scheme 1.

\section{Experimental}

\subsection{Materials and characterization}

All reagents used in the experiments were of analytical grade and were used without further purification. High-purity natural graphite (99\%, average size of $200 \mu \mathrm{m})$ was purchased from Infrazone, Korea. The sodium nitrate $\left(\mathrm{NaNO}_{3}\right)$, sulfuric acid $\left(\mathrm{H}_{2} \mathrm{SO}_{4}\right)$, hydrogen peroxide $\left(\mathrm{H}_{2} \mathrm{O}_{2}\right)$, potassium permanganate $\left(\mathrm{KMnO}_{4}\right)$ solutions, and other reagents were purchased from Aldrich Chemical Co., USA and were used as received. The various functional groups present on the GO and Pop-rGO sheets were measured using a Nicolet 6700 infrared spectrophotometer over the spectral range of $4000-400 \mathrm{~cm}^{-1}$. Diffraction data were acquired with a Rigaku high-power X-ray diffractometer. Laser Raman Spectroscopy (LRS) studies were carried out using a WITec Micro-Raman system using a $532 \mathrm{~nm}$ helium-neon laser source. TEM measurements were performed on a JEOL high-resolution transmission electron microscope with an acceleration voltage of $200 \mathrm{kV}$; specimens were prepared by depositing a drop of the sample dispersion onto 300 mesh carbon-coated $\mathrm{Cu}$ grids. The morphologies of the specimens were determined by FE-SEM using a Hitachi cold FE-SEM at 10 $\mathrm{kV}$. CHF experiments used a commercial cylindrically shaped nickel-chrome wire (nichrome, 80/20). The images of the Multimode V AFM microscope (VEECO, US) were treated by a flattening algorithm using the Nanoscope software and the surface roughness average $\left(R_{\mathrm{a}}\right)$ was calculated using the instrument's vendor software. The hydrophobicity of the nichrome wire surface was determined on the basis of the contact angle (CA) of the water droplet using the sessile drop method of $0.5 \mu \mathrm{L}$ volume (Goniometer, DSA100; KRUSS GmbH, Hamburg, Germany).

Thermal conductivity was measured at room temperature using the Lambda system (Nietzsche, Germany). In this transient hot wire system, a thin platinum wire was suspended in the base liquid using a vertical, cylindrical glass container. The platinum wire had a diameter of $76.2 \mu \mathrm{m}$. The hot wire served as an electrical resistance thermometer. The platinum wire was further coated by a thin electrical insulation layer of epoxy. The transient hot wire method measured the temperature and time response of the platinum wire in response to electrical pulses. A Wheatstone bridge heated the platinum wire and simultaneously measured its resistance. The thermal conductivity was then calculated using Fourier's law. The electrical resistance of the platinum wire changed in proportion to temperature variation. Thermal conductivity was estimated by the slope of the straight line between the temperature and the time. The transient hot wire system was calibrated with deionized water at room temperature.

\subsection{Preparation of the thermally modified pop-up reduced graphene oxide (Pop-rGO) ${ }^{37,38}$}

In an empty $400 \mathrm{~mL}$ beaker, we suspended $200 \mathrm{mg}$ of dried GO sheets $[\mathrm{ESI} \dagger]$. Then, the beaker was covered with aluminum foil that had many punched pores made by a needle. We put the beaker on a muffle furnace at $450{ }^{\circ} \mathrm{C}$ for $15 \mathrm{~min}$. The resulting highly porous black pop-up reduced GO floppy powder (PoprGO, $\sim 110 \mathrm{mg}$ ) was collected after cooling and used as such for our nucleate pool boiling experiments. The preparations of graphene oxide (GO) and reduced graphene oxide (rGO) are reported in the experimental part of the ESI. $\dagger^{18,19}$ 


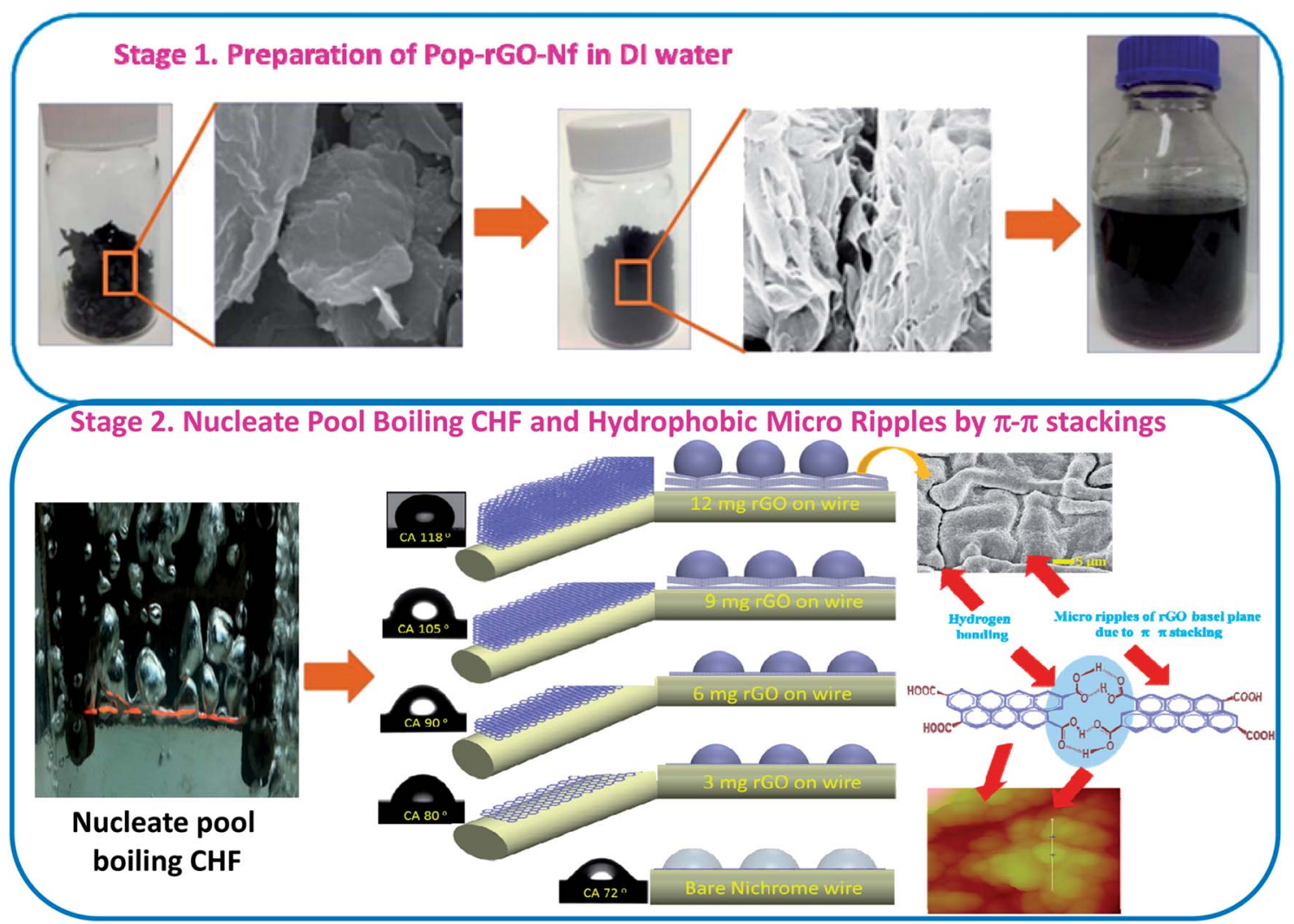

Scheme 1 Schematic illustration of built-up micro ripples from $\pi-\pi$ stacked Pop-rGO-Nfs for extended critical heat flux (CHF).

\subsection{Nucleate pool boiling CHF experiments}

A schematic illustration of the experimental apparatus is shown in Fig. 1. The pool boiling apparatus consisted of the main pool containing the working fluid, the nichrome wire heater, and the data acquisition system. The main pool consisted of a $200 \times$ $100 \times 200 \mathrm{~mm}$ rectangular Pyrex glass bath containing $3 \mathrm{~L}$ of working fluid. The bath was placed on a hot plate (DAIHAN, HP$30 \mathrm{D}, 2 \mathrm{~kW}$ ) for heating and for maintaining the working fluid at the saturated conditions. The bath was sealed using a Teflon cover, whereby a reflux condenser was installed to prevent loss of the working fluid due to evaporation and to maintain atmospheric pressure. The nichrome wire heater, which was $0.2 \mathrm{~mm}$ in diameter and $79.2 \mathrm{~mm}$ in length, was submerged in the working fluid and arranged horizontally by suspending it under tension between the two cylindrical $40 \mathrm{~mm}$-diameter stainless steel electrodes. All the wires used were cleaned to remove any residual dust or contamination on the surface. The electrodes were mounted on the Teflon cover and connected to a direct current (DC) power supply (Sorensen, 60 V/500 A). A data acquisition system (DAQ) (Agilent, 34970A) was employed to measure the voltage applied to the wire heater, and a $1 \Omega$ resistor $( \pm 0.001 \Omega)$ in series with the heater was used to measure the current as a resistance reference. This resistor was cooled and maintained at $10{ }^{\circ} \mathrm{C}$ using a constant temperature bath (Jeiotech, RW-3040G).

The working fluids were preheated on the hot plate for $2 \mathrm{~h}$ for degassing prior to the experiments and were kept in the saturated conditions under atmospheric pressure during the experiments. The heat flux applied to the wire continuously increased at a rate of $50 \mathrm{~kW} \mathrm{~m}{ }^{-2} \mathrm{~min}^{-1}$ until the CHF was reached. When the CHF was reached, the temperature of the wire increased rapidly, causing it to melt. The CHF was calculated as follows:

$$
q \mathrm{CHF}=V_{\max } I_{\max } / A
$$

$V_{\max }$ and $I_{\max }$ are the voltage and current immediately prior to the wire melting, and $A$ represents the heat-transfer area of the heater (nichrome wire). The experimental uncertainty was determined using this equation.

\section{Results and discussion}

For the preparation of Pop-rGO, the GO powder was placed in a beaker, covered with a punched aluminum foil, and put into a muffle furnace at $450{ }^{\circ} \mathrm{C}$ for $15 \mathrm{~min}$ in ambient conditions. After 5 minutes, the brown GO started popping up and transformed into black floppy Pop-rGO powder. The as-prepared PoprGO sheets were examined by FE-SEM and TEM, and the results are shown in Fig. 2. It can be seen that the Pop-rGO powder was separated into individual sheets with a regular porous structure, and this exhibited a typical regular crumpled multi-folds morphology with free-flowing air gaps, as shown in Fig. 2a and $b$. The porous multi-folds appeared because the GO sheets strongly popped-up by thermal treatment for a specified period 


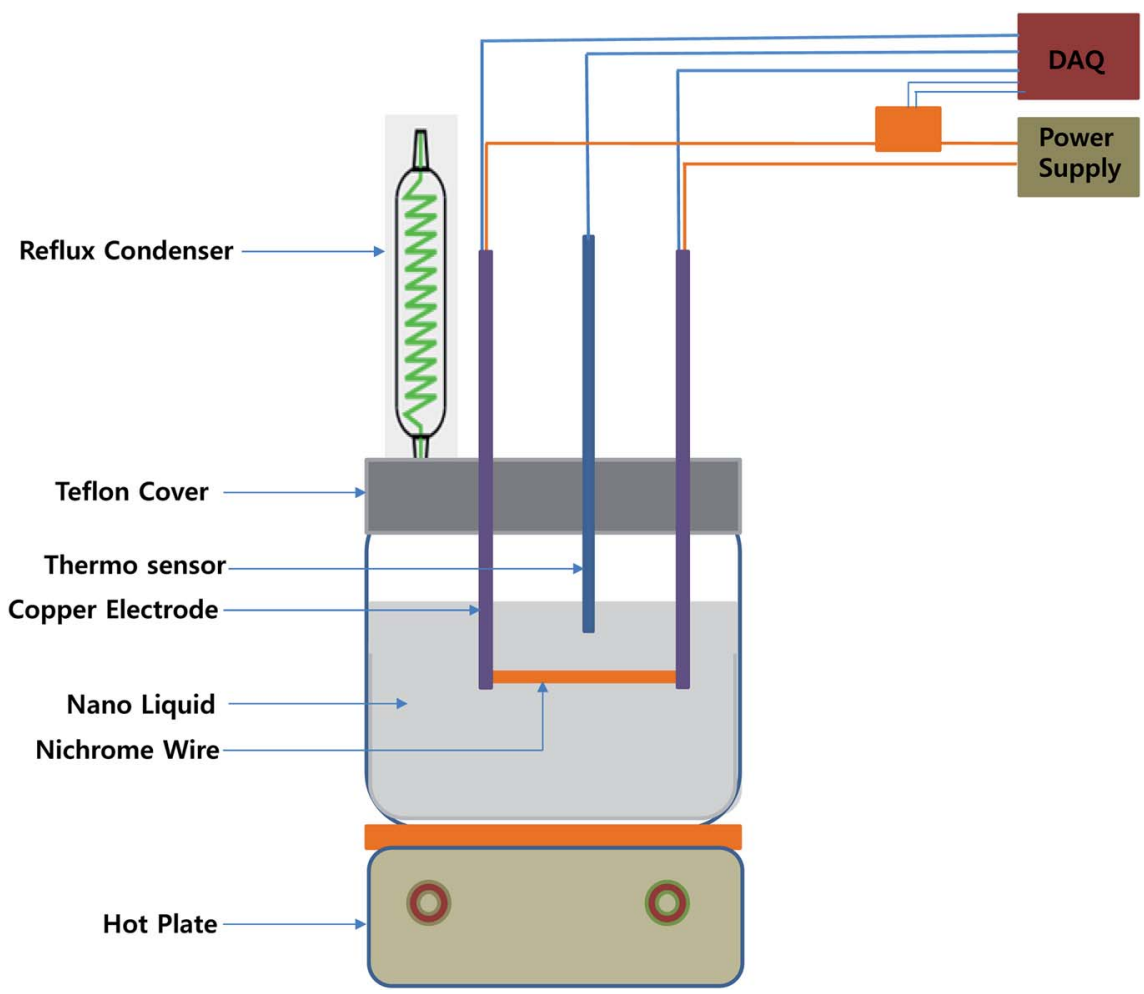

Fig. 1 Schematic illustration of the pool boiling CHF experimental apparatus.

of time. The Pop-rGO was shown to have a high surface area $\left(432 \mathrm{~m}^{2} \mathrm{~g}^{-1}\right)$ due to its highly porous nature. ${ }^{38}$ The TEM image further explained the thickness of the Pop-rGO layered sheets at the nanoscale. Fig. $2 \mathrm{c}$ and the high-resolution image represent the nanostructure of the Pop-rGO, as seen in Fig. $2 \mathrm{~d}$, and the multi-layered Pop-rGO sheets were shown to have higher surface hydrophobicity than the layered Pop-rGO sheets, due to the increasing sheet thickness by $\pi-\pi$ stacking between each individual sheet. These results have been evidenced by the CAs on the wire surface after the pool boiling experiments, as shown in Fig. 3.

\subsection{Extended critical heat flux (eCHF)}

Built-up monolayers on the wire surface influence the nucleation site density and departure diameter that helps a bubble to develop and grow. ${ }^{\mathbf{1 2}}$ The deposition of nanoparticles as a nano or microlayer on the heating wire surface can enhance significantly the critical heat flux values by changing the surface morphologies. CHF enhancement can be explained by increasing the wettability and roughness of the wire surface. We tested various nanofluids, including $\mathrm{Al}_{2} \mathrm{O}_{3}$, $\mathrm{CuO}, \mathrm{CuO}-\mathrm{GO}, \mathrm{GO}$, C-rGO, $x$ GNP, and Pop-rGO-Nfs, on their ability to enhance the CHFs. Among these, Pop-rGO-Nf exhibited superior CHF values at a particular concentration. Fig. 3 and Table 1 (ESI $\dagger$ ) show the pool boiling CHF experimental data along with the data of the prediction model. Kandlikar's prediction model is well-known in the literature for pool boiling experiments that incorporate surface morphology, bubble growth, and contact angle parameters. The contact angle is an alternative way to quantify the wettability of the deposited surface. ${ }^{32}$ Thus, the porous built-up rippled microstructures increase the effective contact area on the surface of the heating wire, and this also significantly contributes to reducing the contact angle on its surface.

Significant heat flux enhancement can be expected on the novel porous micro-rippled structures on the wire surface for Pop-rGO-Nfs in the pool boiling experiment, as shown in Fig. 1 and eqn (1). The heat flux was obtained at values of $q^{\prime \prime}=226134$ $\mathrm{kW} \mathrm{m}{ }^{-2}, 264333 \mathrm{~kW} \mathrm{~m}{ }^{-2}, 339202 \mathrm{~kW} \mathrm{~m}{ }^{-2}, 327895 \mathrm{~kW} \mathrm{~m}^{-2}$ and $1098470 \mathrm{~kW} \mathrm{~m}^{-2}$ for $0.0005 \mathrm{vol} \%, 0.001 \mathrm{vol} \%, 0.005 \mathrm{vol} \%$, and 0.01 vol\%, respectively, of Pop-rGO-Nfs and in DI water at a given constant resistance of $3.3594106 \mathrm{ohms}$, as seen in Fig. 3a. The heat flux was increased gradually by increasing the concentrations of the Pop-rGO-Nfs with respect to DI water. Furthermore, the micro-rippled structures promoted the hydrophobicity and heat flux up to when the saturation point was reached for Pop-rGO-Nf (0.001 vol\%), and declined the heat flow between the working fluid and the heat source by improving the thickness of the $\pi-\pi$ stacking on the wire surface.

The novel micro-rippled structures were shown to be hydrophobic in nature, with higher contact angles and extended $\mathrm{CHF}$ values. For our CHF studies, we used 0.0005 vol\%, $0.001 \mathrm{vol} \%, 0.005 \mathrm{vol} \%$, and 0.01 vol\% of Pop-rGO-Nfs in DI water. The enhancement in CHF was increased up to $132 \%$, $156 \%$, and $175 \%$ from $0.0005 \mathrm{vol} \%, 0.001 \mathrm{vol} \%$, and $0.005 \mathrm{vol} \%$, respectively, of Pop-rGO-Nfs in DI water and their corresponding CAs were $85^{\circ}, 92^{\circ}$, and $105^{\circ}$, respectively, as shown in Fig. 3b. The rational decline in CHF enhancement was observed 

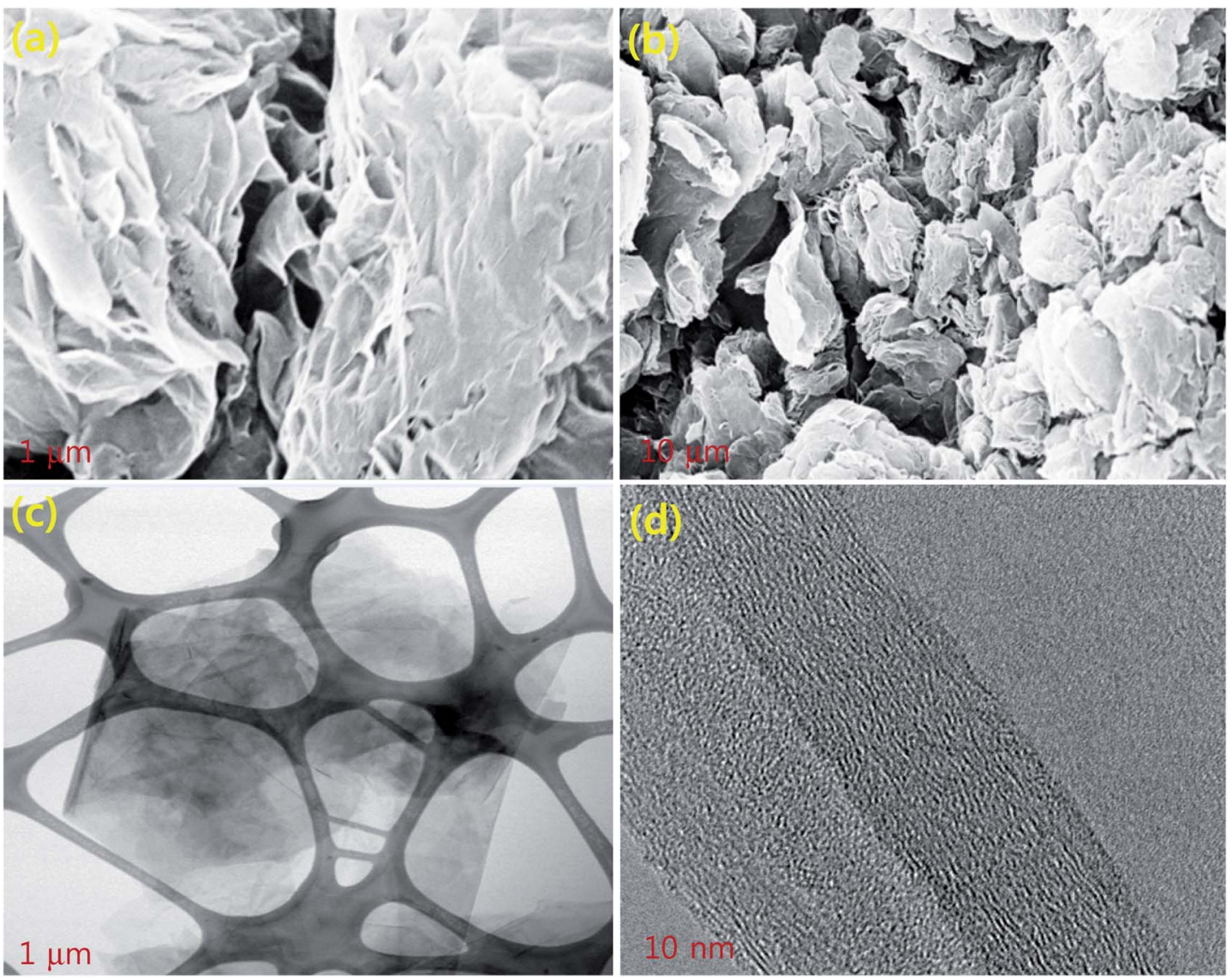

Fig. 2 FE-SEM images of (a) $\pi-\pi$ stacked Pop-rGO individual sheets with air gaps; (b) few-layered Pop-rGO bundles; (c) few-layered Pop-rGO sheets, and (d) the Pop-rGO TEM image.

when $\mathrm{Nf}$ concentrations were greater than $0.001 \mathrm{vol} \%$, in particular 0.05 vol\% of Pop-rGO-Nf provided a CHF enhancement of up to only $153 \%$. The Pop-rGO film on the built-up wire surface consisted of uniform long rippled structures and domains. In addition, the rippled structures had nano-scale cavities, and they provided capillarity to facilitate continuous vapor formation, while the large pores maintained a high permeability, which allowed both penetrations of liquid into the pores of the Pop-rGO film and the escape of vapor bubbles from the Pop-rGO film. Therefore, the porous structure of the PoprGO film improved the migration of the departing vapor bubbles and the liquid impeded the development of a vapor blanket, which could degrade both CHF and HTC, inside the porous structure of the Pop-rGO film. The results indicate that pool boiling employing a Pop-rGO film can dissipate the heat flux to a greater extent, allowing the enhancement of the cooling performance in existing two-phase heat transfer devices. Due to this fact, our results suggested that the Pop-rGO-Nfs showed that their CHF enhancement was increased maximally up to $132 \%, 156 \%$, and $175 \%$ from $0.0005 \mathrm{vol} \%, 0.001 \mathrm{vol} \%$, $0.005 \mathrm{vol} \%$, respectively, and that their CHF values decreased with higher concentrations, as well as showing an increase in hydrophobicity. Moreover, the addition of Pop-rGO film texturing can permit the downsizing of devices and could accommodate further miniaturization of electronics, assuming that the cooling performance of next-generation electronics is similar to that of those currently in use. Similarly, when results were obtained from $\mathrm{ZrO}_{2}, \mathrm{Al}_{2} \mathrm{O}_{3}$ and CNTs in DI water nanofluids, the CHF decreased with increasing concentration.

Next, we examined the enhancement of CHF using other nanofluids such as $\mathrm{CuO}, \mathrm{Al}_{2} \mathrm{O}_{3}, \mathrm{CuO}-\mathrm{GO}, \mathrm{GO}, \mathrm{C}-\mathrm{rGO}$, and $x \mathrm{GNP}-$ Nfs. The CHF enhancement with GO and C-rGO-Nfs followed a similar trend to Pop-rGO-Nf. In contrast, the $\mathrm{CuO}, \mathrm{CuO}-\mathrm{GO}, \mathrm{Al}_{2} \mathrm{O}_{3}$ and $x \mathrm{GNP}$ Nfs showed higher CHF values with higher concentrations due to an increasing of hydrophilicity on the surface, and they showed lower CAs, as these particular Nfs followed Kandlikar's prediction model. ${ }^{32}$ In particular, the metal oxide Nfs followed a similar trend in $\mathrm{CHF}$ increments, for example, $\mathrm{Al}_{2} \mathrm{O}_{3}, \mathrm{CuO}$, CuOGO and $x$ GNP-Nfs had increased CHF values with increased concentration, at the same time as their CAs were reduced. This indicates further that when the deposition layer on the wire surface is increased, the hydrophilicity also increases during nucleate pool boiling. However, in the case of modified graphene oxide based Nfs (i.e. GO, C-rGO and Pop-rGO-Nfs), the CHF initially increased up to a certain concentration and then decreased due to reaching the saturation point of both nucleate heat flux and CHFs. The characteristic features of various commercially available nanofluids were determined after CHF and TC experiments. Mainly, the contact angles were determined using a sessile drop method to confirm whether the built-up nanolayer was hydrophilic or hydrophobic on 

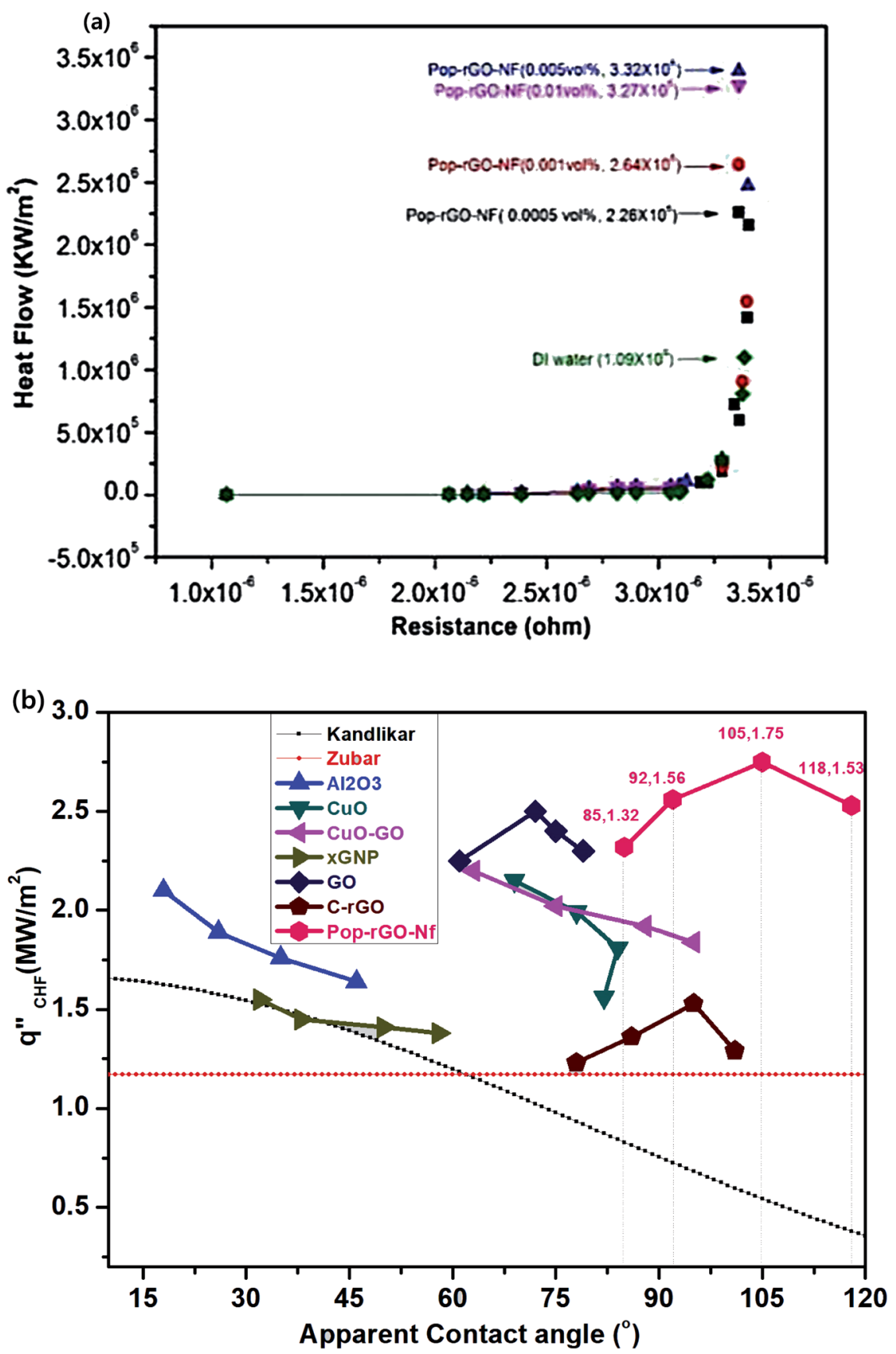

Fig. 3 (a) Nucleate heat flow of Pop-rGO-Nfs on the NiCr wire surface and (b) comparison between the experimental data of various Nfs and the prediction model data of the pool boiling experiments.

the wire surface, in agreement with the literature cited examples, as shown in Table 1. More importantly, the mechanism of the critical heat flux is explained by the schematic representation with suitable references and our previous work in Section 1 of the ESI. $\dagger^{16}$

\subsection{Contact angle analysis of the surface following Pop-rGO deposition}

After pool boiling, we found that the Pop-rGO layer was deposited with a special morphology onto the wire surface, rather than with a smooth surface morphology. This is a significant difference to $3 \mathrm{D}$ self-assembled porous rGO and GO structures reported in the literature. The interaction between the Pop-rGO nanoflakes has a strong influence on the morphology of the deposited structure. The repulsive forces between molecules are related to the activation between nanoflakes that can have an influence on the morphology. It is impossible to distinguish the differences between the upside and downside of the heating wire in the test pool in terms of the deposition of nanoflakes. This means that the formation of the nanoflake surface coating is mainly attributed to the nucleation 
Table 1 Pool boiling CHF values of various nanofluids and contact angles

\begin{tabular}{|c|c|c|c|c|}
\hline Sl. no. & $\mathrm{Nf}$ in DI water & Conc. $^{a}$ vol $\%$ & $\mathrm{CHF}^{b}(\%)$ & $\mathrm{CA}^{c}\left({ }^{\circ}\right)$ \\
\hline 1 & Bare NiCr wire & & & 72 \\
\hline \multirow[t]{4}{*}{2} & \multirow{4}{*}{$\mathrm{Al}_{2} \mathrm{O}_{3}$} & 0.0005 & 64 & 46 \\
\hline & & 0.001 & 76 & 35 \\
\hline & & 0.005 & 89 & 26 \\
\hline & & 0.01 & 110 & 18 \\
\hline \multirow[t]{4}{*}{3} & \multirow[t]{4}{*}{$\mathrm{CuO}$} & 0.0005 & 56 & 82 \\
\hline & & 0.001 & 81 & 84 \\
\hline & & 0.005 & 99 & 78 \\
\hline & & 0.01 & 115 & 69 \\
\hline \multirow[t]{4}{*}{4} & \multirow[t]{4}{*}{$\mathrm{CuO}-\mathrm{GO}$} & 0.0005 & 84 & 95 \\
\hline & & 0.001 & 92 & 88 \\
\hline & & 0.005 & 102 & 75 \\
\hline & & 0.01 & 120 & 63 \\
\hline \multirow[t]{4}{*}{5} & \multirow[t]{4}{*}{$x \mathrm{GNP}$} & 0.0005 & 38 & 58 \\
\hline & & 0.001 & 41 & 50 \\
\hline & & 0.005 & 45 & 38 \\
\hline & & 0.01 & 55 & 32 \\
\hline \multirow[t]{4}{*}{6} & \multirow[t]{4}{*}{ GO } & 0.0005 & 125 & 61 \\
\hline & & 0.001 & 150 & 72 \\
\hline & & 0.005 & 140 & 75 \\
\hline & & 0.01 & 130 & 79 \\
\hline \multirow[t]{4}{*}{7} & \multirow[t]{4}{*}{ C-rGO } & 0.0005 & 23 & 78 \\
\hline & & 0.001 & 36 & 86 \\
\hline & & 0.005 & 53 & 95 \\
\hline & & 0.01 & 29 & 101 \\
\hline \multirow[t]{4}{*}{8} & \multirow[t]{4}{*}{ Pop-rGO } & 0.0005 & 132 & 85 \\
\hline & & 0.001 & 156 & 92 \\
\hline & & 0.005 & 175 & 105 \\
\hline & & 0.01 & 153 & 118 \\
\hline
\end{tabular}

${ }^{a}$ Before the CHF experiments, all of the nanoparticles were dispersed in DI water and sonicated for $1 \mathrm{~h} .{ }^{b} \mathrm{CHF}$ enhancement experiments were performed on a commercially available cylindrically shaped nickelchrome wire (nichrome 80/20). ${ }^{c}$ Contact angle (CA) measurements were performed using the sessile drop method using $0.5 \mu \mathrm{L}$ on the wire surface.

of vapor bubbles on the cylindrical wire and is not due to the gravitational sedimentation of the Pop-rGO nanoflakes. Kim et al. have reported the significant flower and patch-like morphological structures on the wire surface from various vol\% of $\mathrm{Al}_{2} \mathrm{O}_{3} \mathrm{Nf}$ during pool boiling. ${ }^{36}$ In our case, the nucleation bubbles start from the coating of nanoflakes onto the heater wire, nourished within the short time period when the nucleate pool boiling experiments begin. Next, the surface morphology is changed by various nano to micro-scaled nanoflakes being dispersed in the Nfs, but the nature of the material of the heater is not changed. In addition, the characteristics of the nanoflake surface coating are highly dependent on the concentration of the Nfs, as shown in Fig. 4. In the case of the Pop-rGO-Nf with the lowest particle concentration, $0.0005 \mathrm{vol} \%$, the surface shows only a nominal change, as seen in Fig. 4d, e, and $\mathrm{f}$. The continuous wave-like rippled structures are formed on the wire surface due to aggregation of Pop-rGO single sheets, exclusively at $0.001 \mathrm{vol} \%, 0.005 \mathrm{vol} \%$ and $0.01 \mathrm{vol} \%$ of Pop-rGONfs at a heat flux of $q^{\prime \prime}=264333 \mathrm{~kW} \mathrm{~m}^{-2}, 339202 \mathrm{~kW} \mathrm{~m}^{-2}$ and $327895 \mathrm{~kW} \mathrm{~m}^{-2}$, respectively. This indicates that the selfassembly of few-layered Pop-rGO sheets has been constructed by a built-up layer of stacking interactions through benzene localized sextets at basal planes and by aggregations from van der Waals forces. When we used a higher concentration of 0.05 vol\% of Pop-rGO-Nf dispersion, the height of the rippled structures on the wire surface increased, in order to obtain a high roughness average. However, as the concentration increased, the surface deposition of the nanoflakes thickened and micro-ripples were formed on the heating wire surface due to the accumulation of Pop-rGO nanoflakes. It is clearly suggested that for the formation of a rippled network on the wire surface by $\pi-\pi$ stacking interactions, we need a specific vol\% of Pop-rGO-Nf dispersion, as shown in Fig. $4 \mathrm{~h}, \mathrm{k}$, and n. Regular channels were also found between each two long rippled structures that may be the chelation of adjacent carboxylic acid functional groups from individual Pop-rGO sheets through the formation of hydrogen bonds, as shown in Fig. 4i, l, and o.

Subsequently, we investigated the wettability and contact angles (CAs) through the surface hydrophobicity by the built-up layers of Pop-rGO-Nfs, compared against the bare nichrome wire as a control. The advancing angles were determined by the sessile dropping method using $0.5 \mathrm{~mL}$ of DI water. The bare wire surface showed the CA at $72^{\circ}$ and the built-up rippled structures from few-layers to multi-layers of the Pop-rGO nanoflakes deposited on the wire surface presented CAs at $82^{\circ}, 90^{\circ}, 105^{\circ}$ and $118^{\circ}$ with $0.0005 \mathrm{vol} \%, 0.001 \mathrm{vol} \%$, $0.005 \mathrm{vol} \%$, and $0.01 \mathrm{vol} \%$ of Pop-rGO-Nf dispersions, respectively, as seen in the inset images of Fig. $4 a-c, d-f, g-i, j-l$ and $\mathrm{m}-\mathrm{o}$. The surface hydrophobicity was gradually increased by aggregation of ordered porous $\pi-\pi$ stacked layer-by-layer PoprGO nanoflakes with a height of $\sim 5$ to 8 microns, shown in Fig. 4a. In addition, the thickness of the micro-ripples gradually increased with increasing vol\%, evidencing further that the $\pi-\pi$ stacking interactions were strongly endured on the wire surface during the CHF experiments, as shown in Fig. $4 \mathrm{~b}, \mathrm{e}, \mathrm{h}, \mathrm{k}$, and $\mathrm{n}$. The superior hydrophobicity (CA of $118^{\circ}$ ) was achieved at 0.01 vol\% of Pop-rGO-Nf dispersion, which, on the deposited built-up layer, can show the high intensity of multi-layered ripples with regular $\pi-\pi$ stacking interactions, as seen in Fig. $4 \mathrm{n}$. Furthermore, we also investigated the confirmation of the Pop-rGO micro-ripples after the CHF experiments using FESEM images, see Section 2 of the ESI. $\dagger$

\subsection{AFM}

Atomic force microscopy (AFM) was used to analyze topological variations of the bare nichrome wire surface and of the PoprGO-Nf deposited wires, as shown in Fig. 5. The bare wire surface revealed a smooth surface with an average surface roughness $\left(R_{\mathrm{a}}\right)$ of $1.3 \mathrm{~nm}$ shown in Fig. $5 \mathrm{a}$. The $0.0005 \mathrm{vol} \%$ of Pop-rGO-Nf led to the formation of several irregular crests and troughs on the coated wire surface and the $R_{\mathrm{a}}$ value was $\sim 15.07 \mathrm{~nm}$, as shown in Fig. 5b. The surface revealed $R_{\mathrm{a}}$ values of $60.47,254.47$, and $329.80 \mathrm{~nm}$ for $0.001 \mathrm{vol} \%, 0.005 \mathrm{vol} \%$, and 0.01 vol\%, as shown in Fig. $5 \mathrm{c}-\mathrm{e}$, respectively. These novel rippled structures consisted of regular nanocavities due to the regular layer-on-layer network through the $\pi-\pi$ stacking interactions. In addition, nanocavities were found on the rippled 


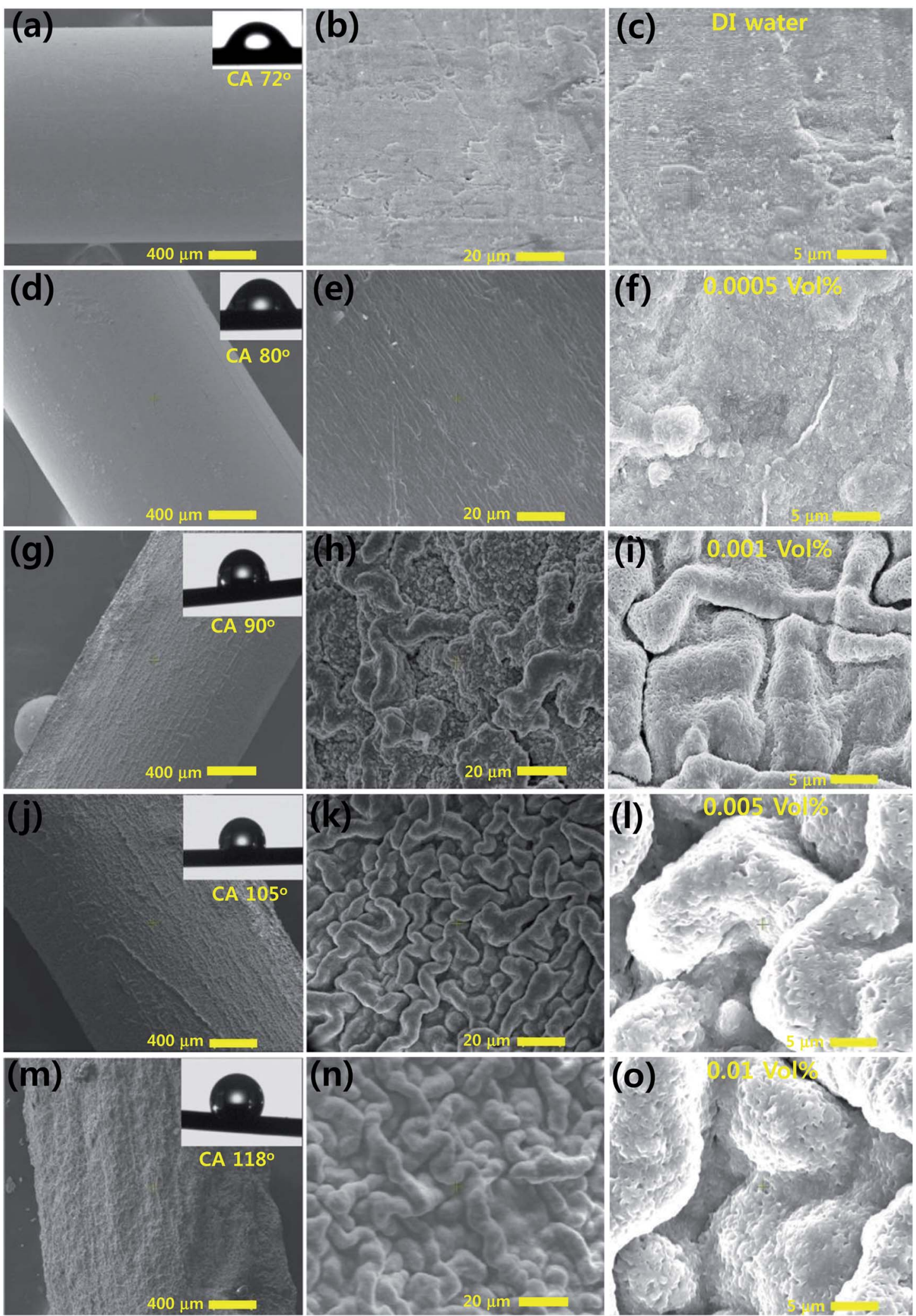

Fig. 4 FE-SEM images of built-up Pop-rGO micro-ripple layers and their corresponding contact angles (CAs): bare wire (a-c); 0.0005 vol\% (d-f); 0.001 vol\% (g-i); 0.005 vol\% $(j-l) ; 0.05$ vol\% $(m-0)$.

structures that represent the hydrogen bonds of carboxylic acids at the edges of the Pop-rGO nanoflakes. However, the nanocavities strongly helped to dissipate the air bubbles generated during nucleate pool boiling and could stabilize the CHF values. The $R_{\mathrm{a}}$ results further support the increase in hydrophobicity of the wire surface that was determined by the CA results (Fig. 4). 

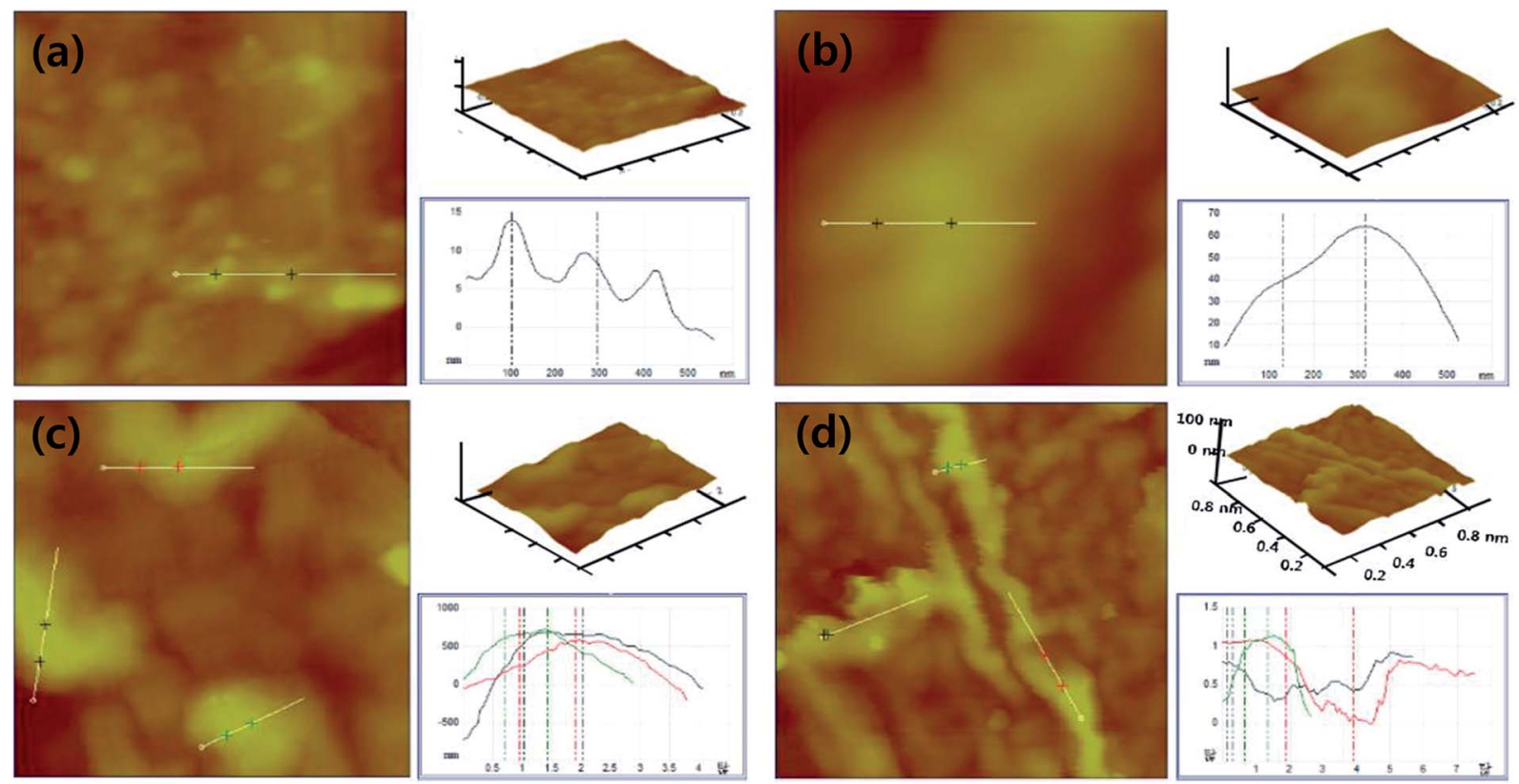

Fig. 5 Atomic force microscopy (AFM) images (left), three-dimensional (3D) images (upper right), and surface cross-sectional profiles (lower right) of (a) a bare nichrome wire $\left(R_{\mathrm{a}} \sim 1.3 \mathrm{~nm}\right)$, and (b) 0.0005 vol\% $\left(R_{\mathrm{a}} \sim 15.07 \mathrm{~nm}\right)$, (c) 0.001 vol\% $\left(R_{\mathrm{a}} \sim 60.47 \mathrm{~nm}\right),(\mathrm{d}) 0.005 \mathrm{vol} \%\left(R_{\mathrm{a}} \sim 254.47\right.$ $\mathrm{nm})$, and (e) 0.01 vol\% ( $\left.R_{\mathrm{a}} \sim 329.80 \mathrm{~nm}\right)$ Pop-rGO-NF coated nichrome wires.

\subsection{FTIR, Raman, XRD, and TGA}

Fig. 6a shows that the FT-IR spectra of GO, C-rGO and Pop-rGO are in good agreement with the literature examples. The stretching vibrational bands of the $\mathrm{OH}$ (hydroxyl), $\mathrm{CO}$ (carbonyl), $\mathrm{COOH}$ (carboxylic acid), and COC (epoxy) functional groups of GO appear at 3415, 1726, 1624, 1425 and $1085 \mathrm{~cm}^{-1}$, respectively. The as-prepared chemically reduced $\mathrm{GO}(\mathrm{rGO})$ showed characteristic bands at 3323, 1732, 1560 and $1210 \mathrm{~cm}^{-1}$, which correspond to the $\mathrm{OH}, \mathrm{CO}, \mathrm{C}=\mathrm{C}$ groups, respectively. In the case of Pop-rGO, it showed characteristic vibrational bands at $3293 \mathrm{~cm}^{-1}$ for the $\mathrm{OH}$ group, $2923 \mathrm{~cm}^{-1}$ for the $\mathrm{CH}$ and $\mathrm{CH}_{2}$ groups, $1653 \mathrm{~cm}^{-1}$ and $1572 \mathrm{~cm}^{-1}$ for the CO group, and $1215 \mathrm{~cm}^{-1}$ for the $\mathrm{C}=\mathrm{C}$ group. ${ }^{34}$ These results confirm the presence of carboxylic acid groups adjacent to the Pop-rGO sheets, and these characteristic bands are shifted to $3293 \mathrm{~cm}^{-1}$ and $1572 \mathrm{~cm}^{-1}$ as broad bands. ${ }^{37}$

In addition, the as-prepared GO exhibited two remarkable Raman peaks at about $1345 \mathrm{~cm}^{-1}$ and $1590 \mathrm{~cm}^{-1}$, corresponding to the well-defined D and $\mathrm{G}$ bands, respectively, as shown in Fig. $6 \mathrm{~b}$. The $\mathrm{G}$ band is related to the $\mathrm{E}_{\mathrm{g}}^{2}$ vibration mode of the $\mathrm{sp}^{2}$ carbon and domains can be used to explain the degree of graphitization, whereas the $\mathrm{D}$ and $2 \mathrm{D}$ bands are associated with structural defects and partially disordered structures of the $\mathrm{sp}^{2}$ domains. After reduction of GO by the thermal heating method, the as-prepared Pop-rGO sample had a G peak at $1584 \mathrm{~cm}^{-1}$ and a D peak at $1354 \mathrm{~cm}^{-1}$, whereas the $\mathrm{D}, \mathrm{G}$ and $2 \mathrm{D}$ peaks for rGO were at $1348 \mathrm{~cm}^{-1}, 1591 \mathrm{~cm}^{-1}$, and $2691 \mathrm{~cm}^{-1}$, respectively. Notably, the three peaks of the Pop-rGO were slightly blueshifted compared to those of the C-rGO. In our investigation, the $I_{\mathrm{D}} / I_{\mathrm{G}}$ ratio of the as-prepared Pop-rGO showed a significant decrease in comparison to the previously reported rGO. In the case of GO, the $I_{\mathrm{D}} / I_{\mathrm{G}}$ ratio was 0.97 and, after the thermal heating method, the ratio for the as-prepared Pop-rGO was 0.74, compared to the ratio of the control C-rGO. We concluded that the production of Pop-rGO from GO by reduction with the thermal heating method had a little healing effect in comparison to the control rGO. ${ }^{35}$ Furthermore, the intensity of the 2D peak at $2708 \mathrm{~cm}^{-1}$ increased for the highly exfoliated Pop-rGO, compared with $\mathrm{rGO}$ that showed better graphitization and no charge transfer due to the absence of impurities.

These FT-IR and Raman results suggested the formation of both rGO and semi-exfoliated Pop-rGO, and also the formation of $\mathrm{sp}^{2}$ carbon networks during the reduction process. In addition, the $\mathrm{sp}^{2}$ planar carbon-carbon systems can support strongly the $\pi-\pi$ stacking interactions of the Pop-rGO sheets, which can convert into a 3D micro-rippled network on the wire surface during the pool boiling experiment.

The interlayer distances of the as-prepared GO and Pop-rGO before and after pool boiling were confirmed by XRD in Fig. 6c, and the as-prepared GO showed a 2 peak at $9.8^{\circ}$, indicating that the graphite was fully oxidized into GO with an interlayer distance of $8.20 \AA^{35}{ }^{35}$ The XRD pattern of Pop-rGO showed typical broad 2 peaks with the polyhydrocarbon template at $21.7^{\circ}$, indicating that the interlayer distance was $4.75 \AA$. The shift of the XRD pattern of GO at $9.8^{\circ}$ to the second peak of Pop-rGO at $21.7^{\circ}$ suggested that the PoprGO was well reduced. The interlayer distance of Pop-rGO was 4.75 $\AA$, which was larger than that of graphite powder $(3.34 \AA)$. After pool boiling, the Pop-rGO was deposited as micro-ripple structures onto the wire surface. The deposited layer on the wire surface was peeled off and submitted for XRD analysis. The XRD pattern of Pop-rGOMR showed a typical broad peak of two peaks with the polyhydrocarbon template at $22.5^{\circ}$, indicating that the interlayer distance was $4.92 \AA$ A. These differences can be attributed to the well- 
(a)

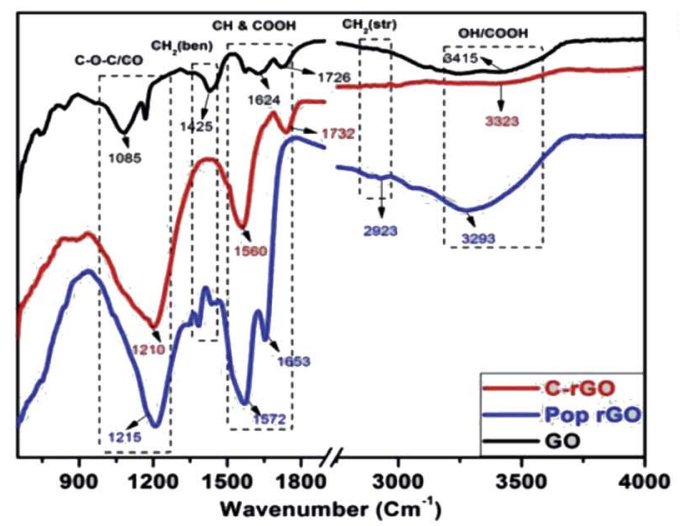

(c)

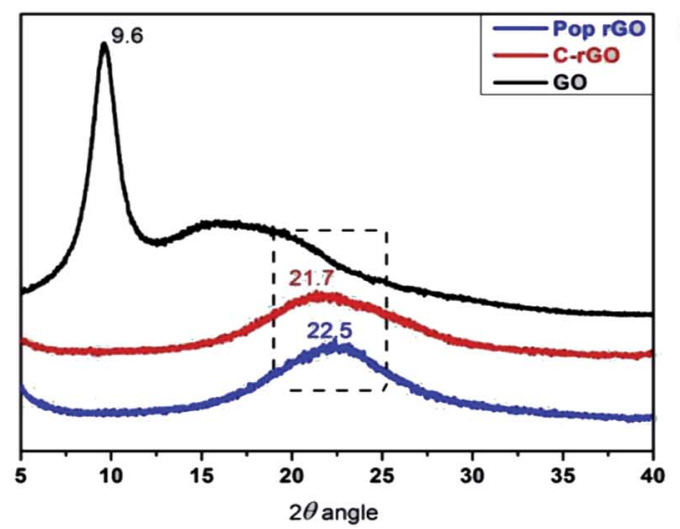

(b)

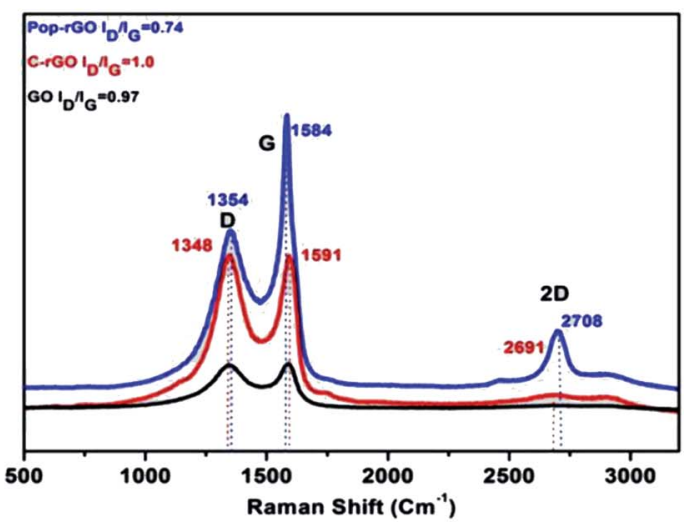

(d)

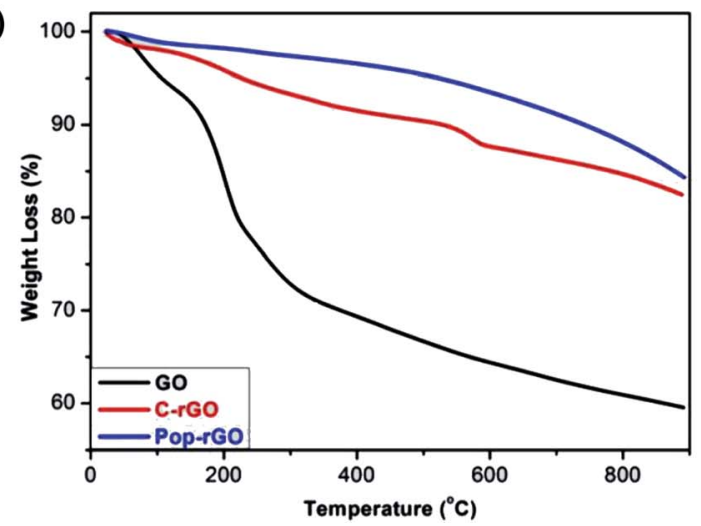

Fig. 6 (a) FT-IR, (b) Raman, (c) XRD, and (d) TGA analysis of Pop-rGO, C-rGO and GO.

ordered 3D structures of the Pop-rGO micro-rippled sheets within the polyhydrocarbon template. After the pool boiling experiment, the two peaks of the Pop-rGO micro-rippled sheets were shifted from $21.7^{\circ}$ to $22.5^{\circ}$, suggesting that Pop-rGO was further reduced due to self-stacking and the removal of air pockets within the nanolayers of Pop-rGO at elevated temperatures.

The quality of the as-prepared Pop-rGO was examined by TGA. The TGA plots of GO, rGO and Pop-rGO are shown in Fig. 6d. In the GO sample, the major weight loss occurred between 100 and $170^{\circ} \mathrm{C}$, indicating the release of $\mathrm{CO}, \mathrm{CO}_{2}$ and water vapor from the most labile functional groups, such as hydroxyl and epoxy, during pyrolysis. At temperatures below $880{ }^{\circ} \mathrm{C}$ the total weight loss was about $40.5 \%$. In contrast, the C-rGO sample showed higher thermal stability than GO. The weight loss was in three steps: $4 \%$ of weight loss at $\sim 200{ }^{\circ} \mathrm{C}, 12 \%$ of weight loss at $572{ }^{\circ} \mathrm{C}$, and the weight loss was about $18 \%$ at $900{ }^{\circ} \mathrm{C}$. This major loss of mass could be attributed to the presence of a high amount of polyhydrocarbon on the as-prepared $\mathrm{C}-\mathrm{rGO}$, whereas after thermally heating the GO, the total weight loss of the as-prepared Pop-rGO was only $16 \%$. This minor mass loss can be attributed to the absence of most oxygen functional groups. ${ }^{35}$

\subsection{Thermal conductivity (TC)}

Graphene has the very high thermal conductivity of 900-5000 W $\mathrm{m}^{-1} \mathrm{~K}^{-1}$ in the 2D planar directions. Therefore, we obtained TC values from the well-ordered Pop-rGO-Nf films deposited during nucleate pool boiling. Balandin, et al. reported the superior TC values of single-layered GO by studying the Raman G peak frequency on the excitation laser power. ${ }^{39}$ The Pop-rGO film may strongly affect the temperature variation underneath the bubbles and inhibit the formation of dry regions by dissipating heat from any local hotspots to neighboring wet regions of lower temperature, resulting in delaying the drying-out process of the microlayer. Therefore, it could delay the onset of the CHF behavior. In our present work, the effect of $\mathrm{TC}$ and the concentration of nanofluids on the CHF enhancement was investigated, whereby the TC values of the GO, rGO, $x \mathrm{GNP}$ and Pop-rGO Nfs were measured in DI water at room temperature $\left(\sim 25^{\circ} \mathrm{C}\right)$ at various concentrations ranging from $0.0005 \mathrm{vol} \%$ to $0.01 \mathrm{vol} \%$. The TC values increased with increasing concentrations, as shown in Fig. 7, and we obtained the highest TC value for Pop-rGO-Nfs compared to the other Nfs in DI water. Recently, J. D. Renteria et al. reported the highest TC values for rGO free-standing films at various temperatures. ${ }^{40}$ These results are in good agreement with our research results from the TC values of Pop-rGO-Nf. In detail, the 0.0005 vol\%, $0.001 \mathrm{vol} \%$, $0.005 \mathrm{vol} \%$, and $0.01 \mathrm{vol} \%$ of Pop-rGO-Nfs showed corresponding higher TC values of 1092, 1096.5, 1101.8 and 1103.7, respectively. These values are double the TC value of DI water. The higher TC values may be attributed due to higher surface area and regular stacking interactions of Pop-rGO-Nf. Finally, we investigated the TCs of GO, rGO, CuO-GO and $x \mathrm{GNP}$ Nfs and their TC values were lower than that of Pop-rGO-Nf. 


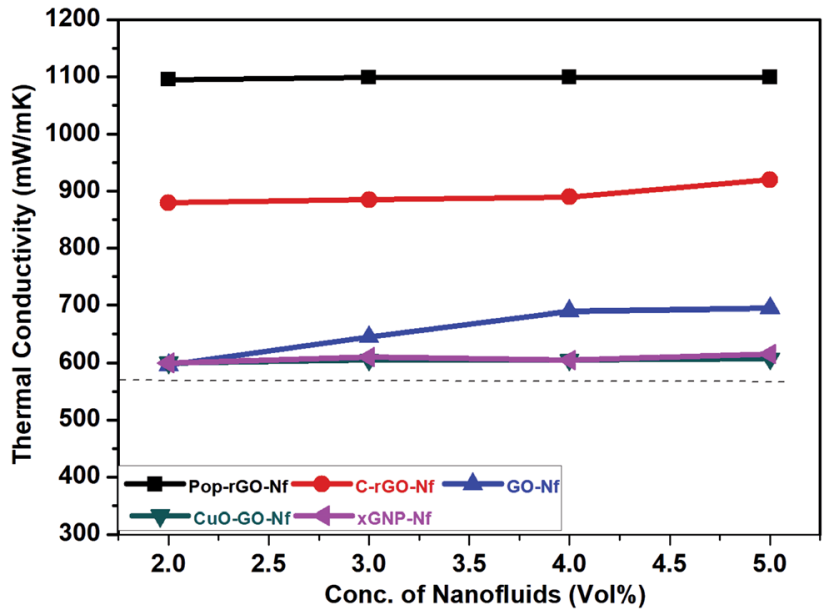

Fig. 7 Thermal conductivities of various nanofluids.

\section{Conclusion}

We have demonstrated highly porous Pop-rGO nanoflakes obtained from GO through a thermal heating process. After heat treatment, GO was reduced to Pop-rGO porous nanoflakes and this was confirmed by FT-IR, XRD, and TGA. Pop-rGO was very compatible with DI water on the nanoscale level to prepare PoprGO-Nfs due to availability of edge centered carboxylic acid groups. We applied Pop-rGO-Nfs for the first time in nucleate pool boiling experiments, resulting in the achievement of higher CHF values, thereby providing higher thermal conductivities and critical heat fluxes. After the nucleate pool boiling experiments, the built-up surface appeared as novel microrippled structures. In addition, when increasing the Pop-rGO$\mathrm{Nf}$ concentrations, the CHF values, heat flux and contact angles also increased. In particular, the Pop-rGO-Nf with 0.005 vol\% showed a superior CHF value of $175 \%$ with a $105^{\circ} \mathrm{CA}$. The obtained $\mathrm{CHF}$ value is far superior to that of the existing graphene-based $\mathrm{Nfs}$ in the literature. The CHF is $153 \%$ using 0.01 vol\% of Pop-rGO-Nf, and this strongly indicates the reaching of the saturation point and the deposited built-up micro-rippled surface showed higher surface hydrophobicity with a CA of $118^{\circ}$. The advantage of the highly hydrophobic surface is that it can strongly support the harvesting of water bubbles even on hot surfaces. The novel rippled structures were confirmed by FE-SEM through $\pi-\pi$ stacking interactions of the Pop-rGO nanoflakes, which were deposited on the wire surface, and their height and width were further determined by FE-SEM and AFM analyses. Next, the regular nanoscale cavities on the rippled structures provide capillarity to facilitate continuous vapor formation, while the large pores maintain a high permeability, and this allows both the penetration of liquid into the pores and the escape of vapor from the Pop-rGO-Nf built-up surface. The present results suggested that pool boiling using Pop-rGO-Nf can dissipate the critical heat flux of electronic chips to a greater extent, allowing the enhancement of cooling performance in existing two-phase heat transfer devices. Moreover, the addition of Pop-rGO-Nf texturing can permit the downsizing of devices and could facilitate further miniaturization of electronics, assuming that the cooling performance of next-generation electronics is similar to that of those currently in use. Based on the present encouraging results, we are currently further exploring the next generation of highperformance high-CHF nanofluids from low-cost materials.

\section{Conflicts of interest}

There are no conflicts to declare.

\section{Acknowledgements}

This work was supported by the National Research Foundation of Korea (NRF) grant funded by the Korean government (MSIP No. 2017R1A2B2011730, No. 2018R1A6A1A03024509 and No. 2019R1A2C1011113).

\section{References}

1 P. Keblinski, S. R. Phillpot, S. U. S. Choi and J. A. Eastman, Mechanisms of heat flow in suspensions of nano-sized particles (nanofluids), Int. J. Heat Mass Transfer, 2002, 45, 855-863.

2 Y. Xuan and W. Roetzel, Investigation on convective heat transfer and flow features of nanofluids, Int. J. Heat Mass Transfer, 2000, 43, 3701-3707.

3 H. U. Kang, S. H. Kim and J. M. Oh, Estimation of thermal conductivity of nanofluid using experimental effective particle volume, Exp. Heat Transfer, 2006, 19, 181-191.

4 S. K. Das, N. Putra, P. Thiesen and W. Roetzel, Temperature dependence of thermal conductivity enhancement for nanofluids, J. Heat Transfer, 2003, 125, 567-574.

5 S. Jana, A. S. Khojin and W. H. Zhong, Enhancement of fluid thermal conductivity by the addition of single and hybrid nano-additives, Thermochim. Acta, 2007, 462, 45-55.

6 H. Zhu, C. Zhang, S. Liu, Y. Tang and Y. Yin, Effects of nanoparticle clustering and alignment on thermal conductivities of $\mathrm{Fe}_{3} \mathrm{O}_{4}$ aqueous nanofluids, Appl. Phys. Lett., 2006, 89, 023123.

7 R. K. Cheedarala, E. J. Park, Y.-B. Park and H. W. Park, Highly wettable CuO:graphene oxide core-shell porous nanocomposites for enhanced critical heat flux, Phys. Status Solidi A, 2015, 212, 1756-1766.

8 R. Iglesias, M. A. Rivas, J. C. R. Reis and T. P. Iglesias, Permittivity and electric conductivity of aqueous alumina (40 nm) nanofluids at different temperatures, J. Chem. Thermodyn., 2015, 89, 189-196.

9 C. H. Li and G. P. Peterson, The effect of particle size on the effective thermal conductivity of $\mathrm{Al}_{2} \mathrm{O}_{3}$-water nanofluids, $J$. Appl. Phys., 2007, 101, 044312.

$10 \mathrm{H}$. Xie, H. Lee, W. Youn and M. Choi, Nanofluids containing multiwalled carbon nanotubes and their enhanced thermal conductivities, J. Appl. Phys., 2003, 94, 4967-4971.

11 E. J. Park, S. D. Park, I. C. Bang, Y.-B. Park and H. W. Park, Critical heat flux characteristics of nanofluids based on 
exfoliated graphite nanoplatelets (xGnPs), Mater. Lett., 2012, 81, 193-197.

12 J. Choi and M. Jeong, Compact, lightweight, and highly efficient circular heat sink design for high-end PCs, Appl. Therm. Eng., 2016, 92, 162-171.

13 J. M. Kim, T. Kim, J. Kim, M. H. Kim and H. S. Ahn, Effect of a graphene oxide coating layer on critical heat flux enhancement under pool boiling, Int. J. Heat Mass Transfer, 2014, 77, 919-927.

14 S. H. S. Ahn, J.-W. Jang, M. Seol, J. M. Kim, D.-J. Yun, C. Park, H. Kim, D. H. Youn, J. Y. Kim, G. Park, C. Park, J. M. Kim, D. I. Yu, K. Yong, M. H. Kim and J. S. Lee, Self-assembled foam-like graphene networks formed through nucleate boiling, Sci. Rep., 2013, 3, 1396.

15 Z. C. Li, Z. Wang, P.-I. Wang, Y. Peles, N. Koratkar and G. P. Peterson, Nanostructured copper interfaces for enhanced boiling, Small, 2008, 4, 1084-1088.

16 R. K. Cheedarala, E. Park, K. Kong, Y. B. Park and H. W. Park, Experimental study on critical heat flux of highly efficient soft hydrophilic CuO-chitosan nanofluid templates, Int. J. Heat Mass Transfer, 2016, 100, 396-406.

17 S. An, D.-Y. Kim, J.-G. Lee, H. S. Jo, M.-w. Kim, S. S. Al-Deyab, J. Choi and S. S. Yoon, Supersonically sprayed reduced graphene oxide film to enhance critical heat flux in pool boiling, Int. J. Heat Mass Transfer, 2016, 98, 124-130.

18 H. S. Ahn, J. M. Kim, C. Park, J.-W. Jang, J. S. Lee, H. Kim, M. Kaviany and M. H. Kim, A novel role of three dimensional graphene foam to prevent heater failure during boiling, Sci. Rep., 2013, 3, 1960.

19 W. S. Hummers and R. E. Offeman, Nucleus-Independent Chemical Shifts: A Simple and Efficient Aromaticity Probe, J. Am. Chem. Soc., 1958, 80, 1339.

20 X. Huang, Z. Zeng, Z. Fan, J. Liu and H. Zhang, Graphenebased electrodes, Adv. Mater., 2012, 24, 5979-6004.

21 R. D. A. Dikin, S. Stankovich, E. J. Zimney, R. D. Piner, G. H. B. Dommett, G. Evmenenko, S. T. Nguyen and S. Ruoff, Preparation and characterization of graphene oxide paper, Nature, 2007, 448, 457-460.

22 C. Lee, X. Wei, J. W. Kysar and J. Hone, Measurement of the elastic properties and intrinsic strength of monolayer graphene, Science, 2008, 321, 385-388.

23 K.-J. Baeg, M. Caironi and Y.-Y. Noh, Toward printed integrated circuits based on unipolar or ambipolar polymer semiconductors, Adv. Mater., 2013, 25, 4210-4244.

24 N. O. Weiss, H. Zhou, L. Liao, Y. Liu, S. Jiang, Y. Huang and $\mathrm{X}$. Duan, Graphene: an emerging electronic material, $A d v$. Mater., 2012, 24, 5782-5825.

25 J. Liu and X.-W. Liu, Two-Dimensional Nanoarchitectures for Lithium Storage, Adv. Mater., 2012, 24, 4097-4111.

26 D. Natali and M. Caironi, Charge Injection in SolutionProcessed Organic Field-Effect Transistors: Physics, Models and Characterization Methods, Adv. Mater., 2012, 24, 13571387.
27 L. Feng, L. Wu and X. Qu, New horizons for diagnostics and therapeutic applications of graphene and graphene oxide, Adv. Mater., 2013, 25, 168-186.

28 P. Fattahi, G. Yang, G. Kim and M. R. Abidian, A review of organic and inorganic biomaterials for neural interfaces, Adv. Mater., 2014, 26, 1846-1885.

29 N. K. Mahanta and A. R. Abramson, in 13th IEEE Intersociety Conference on Thermal and Thermomechanical Phenomena in Electronic Systems (ITherm), 2012, pp. 1-6, http:// www.ithermconference.org/.

30 S. Abdolhosseinzadeh, H. Asgharzadeh and H. Seop Kim, Fast and fully-scalable synthesis of reduced graphene oxide, Sci. Rep., 2015, 5, 10160.

31 T. Ramanathan, A. A. A. Stankovichs, D. A. Dikin, M. H. Alonso, R. D. Piner, D. H. Adamson, H. C. Schniepp, X. Chen, R. S. Ruoff, S. T. Nguyen, I. A. Aksay, R. K. P. Homme and L. C. Brinson, Functionalized graphene sheets for polymer nanocomposites, Nat. Nanotechnol., 2008, 3, 327-331.

32 S. D. Park, S. Won Lee, S. Kang, I. C. Bang, J. H. Kim, H. S. Shin, D. W. Lee and D. Won Lee, Effects of nanofluids containing graphene/graphene-oxide nanosheets on critical heat flux, Appl. Phys. Lett., 2010, 97, 023103.

33 T. T. Baby and R. Sundara, Synthesis and transport properties of metal oxide decorated graphene dispersed nanofluids, J. Phys. Chem. C, 2011, 115, 8527-8533.

34 R. K. Cheedarala, J.-H. Jeon, C.-D. Kee and I.-K. Oh, BioInspired All-Organic Soft Actuator Based on a $\pi-\pi$ Stacked 3D Ionic Network Membrane and Ultra-Fast Solution Processing, Adv. Funct. Mater., 2014, 24, 6005-6015.

35 S. G. Kandlikar, A theoretical model to predict pool boiling CHF incorporating effects of contact angle and orientation, Int. J. Heat Mass Transfer, 2001, 123, 1071-1079.

36 H. Kim, J. Kim and M. H. Kim, Effect of nanoparticles on CHF enhancement in pool boiling of nano-fluids, Int. J. Heat Mass Transfer, 2006, 49, 5070-5074.

37 M. Acik, G. Lee, C. Mattevi, M. Chhowalla, K. Cho and Y. J. Chabal, Unusual infrared-absorption mechanism in thermally reduced graphene oxide, Nat. Mater., 2010, 9, 840-845.

38 S. Some, Y. Kim, Y. Yoon, H. Yoo, S. Lee, Y. Park and H. Lee, High-quality reduced graphene oxide by a dual-function chemical reduction and healing process, Sci. Rep., 2013, 3, 1929.

39 A. A. Balandin, S. Ghosh, W. Bao, I. Calizo, D. Teweldebrhan, F. Miao and C. N. Lau, Superior thermal conductivity of single-layer graphene, Nano Lett., 2008, 8, 902-907.

40 J. D. Renteria, S. Ramirez, H. Malekpour, B. Alonso, A. Centeno, A. Zurutuza, A. I. Cocemasov, D. L. Nika and A. A. Balandin, Strongly anisotropic thermal conductivity of free-standing reduced graphene oxide films annealed at high temperature, Adv. Funct. Mater., 2015, 25, 4664-4672. 